\title{
54. Thioacetamide-Induced Changes in Diploid Cultures of Human Liver
}

\author{
By Tohru OKIGAKI \\ Pasadena Foundation for Medical Research, \\ Pasadena, California 91101, U. S. A. \\ (Comm. by Sajiro Makino, M. J. A., April 12, 1976)
}

Human liver culture and characteristics. It is known that a weak carcinogen thioacetamide (TA) selectively induces nuclear abnormalities of liver cells in experimental animals. ') 'A preliminary study using rat liver cells in culture suggested that this agent (TA) was also able to induce similar nuclear and nucleolar changes in vitro (unpublished). This report is of a similar study using diploid cultures from adult human liver.

The cell cultures used in this study (HL-9 cell line) were grown from liver obtained $90 \mathrm{~min}$ post-mortem from a 59-year-old male. There were no pathological changes associated with any hepatic disease.

A previously described culture method ${ }^{2}$ was applied to this specimen. The medium was Ham's F-12 (Microbiological Associates) supplemented with $10 \%$ fetal bovine serum (Gibco). HL-9 cells in the primary culture, were predominantly epithelial, and appeared strikingly similar to histological sections of liver, with substantial numbers showing binucleation (Fig. 1). Initial fibroblast cell colonies appeared infrequently and grew very poorly. From the 2nd through the 4th passages, the epithelial cells gradually became bipolar or elongated in form and finally showed a homogeneous fibroblast-like morphology in later passages (Fig. 2). Cells analyzed at the 10th and 18th passages contained a diploid number of chromosomes with a normal human male karyotype. No tumorigenicity was found by injecting $2 \times 10^{6}$ cells from these passages into each of 10 neonatal (less than 12 hours post-partum) rats.

The HL-9 cell line persisted through $23 \pm 3$ passages over a period of approximately 6 months. Biochemical analysis at the 10th passage for tyrosine alpha-ketoglutarate transaminase showed no liver specific response. Serum protein assay by immunodiffusion and immunoelectrophoresis at the same passage, using monospecific and multispecific antisera, showed no evidence of albumin or other serum proteins, with the exception of 2-macroglobulin.

Thioacetamide-treatment. Cells stored in liquid nitrogen at 


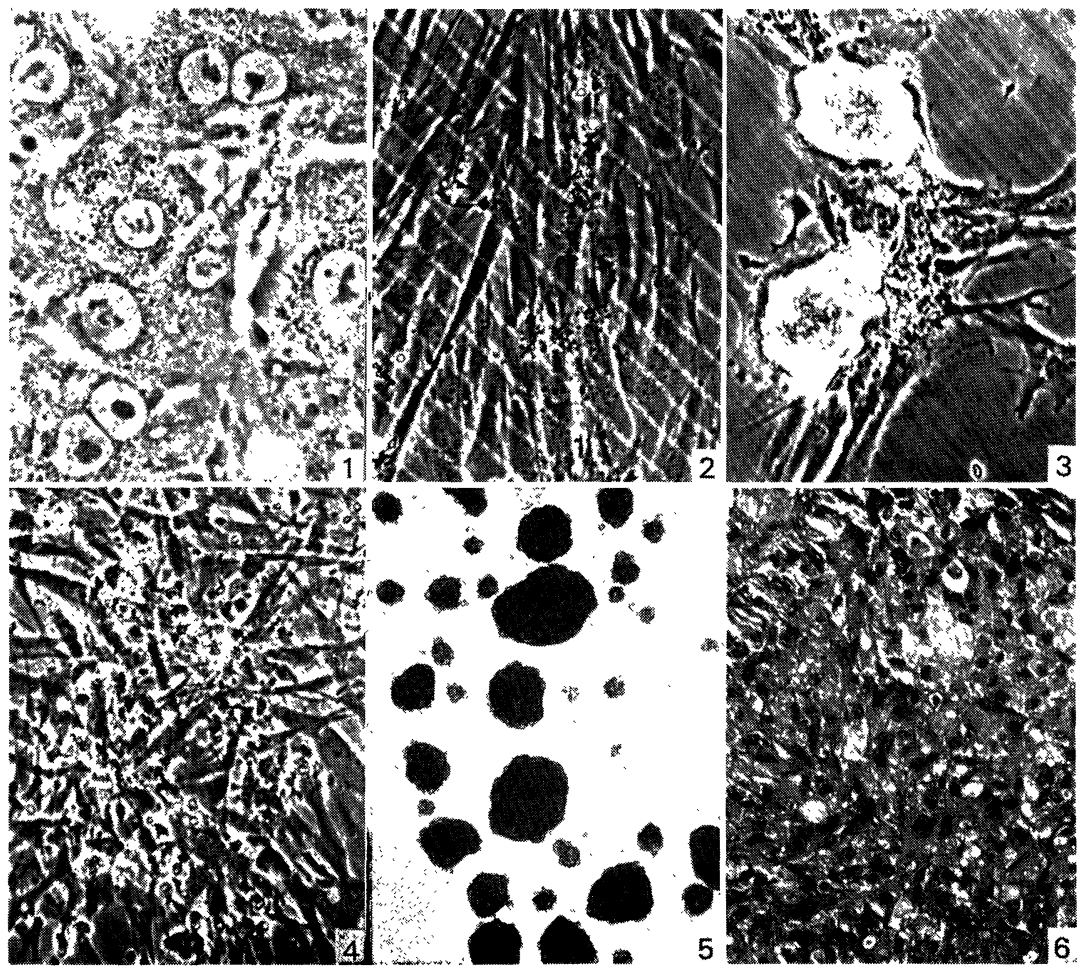

1) HL-9 epithelial cells in primary culture (phase contrast). 2) Cells at passage 10 (untreated control, phase contrast). 3) TA-treated cells showing clusters (phase contrast). 4) TA-treated cells showing criss-cross pattern (phase contrast). 5) Aggregate formation of TA-treated cells, 48 hours in rotation culture (bright field). 6) Histological section of a TA-cell aggregate (H, E stain).

the 4 th passage were thawed and used in this study. TA (Sigma) was chosen for use at $5 \mathrm{mg} / \mathrm{ml}$ in culture medium. Cells were treated continuously for 10 days during their 8th and 9th passages. After treatment the cells were again cultured in control medium.

However, the nuclear abnormality which is normally detectable in cultured rat liver cells was not observed, nor was there any other apparent abnormality immediately after treatment. Two months later during the 18th to 19th passages, signs of morphological irregularity, such as uneven growth of colonies, criss-crossing and piling up, became apparent (Figs. 3, 4). Chromosome analysis at the 25th passage indicated that TA-treated cells did not maintain diploid numbers; $82 \%$ of the cells had become tetraploid (Table I). The cells treated with TA also showed prolongation of lifespan, extending up to 50 subcultures, subsequent to which they gradually died out (Table II).

A rotation culture method $^{3)}$ was used to detect cellular ability 
to form aggregates. At the 20th passage, neither controls nor treated cultures produced cell aggregates in rotation culture. However, in the 30th passage TA-treated cells formed large, spherical aggregates (Table II; Fig. 5). Histological observations indicated that the cell aggregates were generally pleomorphic, and consisted mainly of epithelial cell clusters surrounded by fibroblasts (Fig. 6).

Table I. The chromosome numbers in TA-treated HL-9 cells

\begin{tabular}{cccc}
\hline Cell cultures & $\begin{array}{c}\text { Passages } \\
\text { analyzed }\end{array}$ & $\begin{array}{c}\text { No. cells in } \\
\text { 2n-range }(\%)\end{array}$ & $\begin{array}{c}\text { No. cells in } \\
\text { 4n-range }(\%)\end{array}$ \\
\hline Control & 10 & $468(93.6)$ & $32(6.4)$ \\
Control & 18 & $463(92.6)$ & $37(7.4)$ \\
TA-treated & 25 & $36(18.0)$ & $164(82.0)$ \\
\hline
\end{tabular}

Table II. The cellular properties of HL-9 cells with and without TA-treatment

\begin{tabular}{ccccc}
\hline Cell cultures & $\begin{array}{c}\text { Lifespan } \\
\text { (No. subcultures) }\end{array}$ & Chromosomes & \multicolumn{2}{c}{$\begin{array}{c}\text { Aggregation } \\
\text { 20th }\end{array}$} \\
\hline Control & $23 \pm 3^{(1)}$ & $2 \mathrm{n}$ & -- & non-existent \\
TA-treated & $50 \pm 2^{(2)}$ & $4 \mathrm{n}$ & -- & ++ \\
\hline
\end{tabular}

(1) Average value of 5 separate cultures.

(2) Average value of 3 separate cultures.

Discussion. Cells in tissue culture do not always maintain their initial morphological features.4) Although our epithelial cells from primary cultures evolved into a homogeneous population of elongate, fibroblast-like cells, their epithelial characteristics returned when they assembled into spherical cellular aggregates (Fig. 6). This demonstrated morphological inconsistency of cells in the tissue culture system. HL-9 also lost the functional characteristics of parenchymal cells, leaving their classification obscure. Nevertheless, adult human liver cells were used for this evaluation of a hepatocarcinogen.

In contrast to studies showing carcinogen-induced transformation of mammalian cells in vitro there are no reports of cultures of human cells which have undergone malignant transformation following treatment with chemical carcinogens, despite numerous trials.5) In this study, the human liver HL-9 diploid cells, treated with TA, were not transformed. However, they did respond to carcinogen treatment by showing 1) chromosomal alteration, 2) prolongation of lifespan, and 3) an ability to form cell aggregates. The data imply that carcinogen-induced transformation of diploid human cells might be possible, if the proper conditions were provided. This implication is important as a basis for continuing studies in this field. 
Summary. Human diploid cell cultures from adult male liver were treated with thioacetamide. The control cultures died at around 23 subculture passages. The treated series grew more than double the length of the normal lifespan with noticeably different growth patterns and cells changed into a tetraploid range. The treated cells showed cell aggregates in a rotation culture. No tumorigenicity was found.

Acknowledgement. The author is deeply indebted to: Dr. A. L. Koehler, for supplying autopsy specimens; Dr. L. E. Gerschenson for enzyme assay, and Professor Emeritus Dr. S. Makino for his kind revision. Supported by the Public Health Service, Grant No. CA13376 from the National Cancer Institute.

\section{References}

1) Kleinfeld, R. G. (1957): Cancer Res., 17, 954-962.

2) Okigaki, T., S. G. Quan, and K. S. Narayan (1974) : In Vitro, 9, 630.

3) Arata, T., and T. Okigaki (1972): J. Natl. Cancer Inst., 49, 1445-1447.

4) Okigaki, T., and S. G. Quan (1974) : Proc. Japan Acad., 50, 517-520.

5) Hayflick, L. (1975): Personal Communication. 